\title{
Treatment of ulcerative colitis with fish oil supplementation: a prospective 12 month randomised controlled trial
}

\author{
A B Hawthorne, T K Daneshmend, C J Hawkey, A Belluzzi, S J Everitt, G K T Holmes, \\ C Malkinson, M Z Shaheen, J E Willars
}

\begin{abstract}
The effect of fish oil on the course of ulcerative colitis was investigated in a randomised blinded controlled study. Eighty seven patients received supplements of $20 \mathrm{ml}$ HiEPA fish oil as triglyceride ( $4.5 \mathrm{~g}$ of eicosapentaenoic acid) or olive oil placebo daily for one year. The oils were given in addition to standard drug therapy and trial entry was stratified for disease activity. Fish oil significantly increased the eicosapentaenoic acid content of rectal mucosa to $3.2 \%$ of total fatty acids at six months, compared with $0.63 \%$ for patients on olive oil. This was associated with increased synthesis of leukotriene B5, and 53\% suppression of leukotriene B4 synthesis by ionophore - stimulated neutrophils. Leukotriene B4 suppression persisted for at least two months after treatment was stopped. Treatment with fish oil resulted in measurable, but only limited clinical benefit. For patients entering the trial in relapse $(n=53)$, there was a significant reduction in corticosteroid requirement after one and two months treatment. There was a trend towards achieving remission (off corticosteroids) faster in the patients on fish oil, although differences were not significant. For patients in remission at trial entry or during the trial $(n=69)$, there was no significant difference in the rate of relapse by log rank analysis. We conclude that fish oil supplementation produces a modest corticosteroid sparing effect in active disease, but there is no benefit in maintenance therapy.
\end{abstract}

In ulcerative colitis inflammation is characterised by marked influx and accumulation of neutrophils in the colonic mucosa. There is increasing evidence that leukotriene B4 $4^{a}$ may be pivotal in triggering or perpetuating this accumulation. It is a potent chemotactic factor ${ }^{1}$ present in high levels in inflamed colonic mucosa ${ }^{2}$ where it may account for $80 \%$ of the lipid extractable chemotactic activity. ${ }^{3}$ Treatments which reduce synthesis of leukotriene B4 may therefore be of benefit in ulcerative colitis.

Diets containing high levels of $w-3$ fatty acids, such as eicosapentaenoic acid and docosahexaenoic acid, are known to modify leukotriene production. ${ }^{+5}$ Eicosapentaenoic acid levels in cell membranes rise, with an increase in eicosapentaenoic acid derived lipoxygenase products, such as leukotriene $\mathrm{B}^{6}{ }^{6}$, which has markedly reduced chemotactic potency compared with leukotriene B4. $^{78}$ In addition synthesis of lipoxygenase products derived from arachidonic acid is reduced as a result of diminished substrate release, ${ }^{+}$5-lipoxygenase inhibition, ${ }^{+}$and enzyme inhibition at the level of leukotriene A hydrolase. ${ }^{69}$ Anti inflammatory effects of fish oils have been shown in animal models, ${ }^{10}$ " including a rat model of chronic colitis induced by trinitrobenzene sulfonic acid. ${ }^{12}{ }^{13}$ In clinical studies, fish oils have been reported to have modest anti inflammatory effects in psoriasis, ${ }^{1+}$ atopic dermatitis, ${ }^{15}$ and rheumatoid arthritis. ${ }^{16}$ In ulcerative colitis increased arachidonic acid levels in colonic mucosa have been reported, ${ }^{17} 18$ and this can be decreased by eicosapentaenoic acid supplementation. ${ }^{19}$ Several small preliminary crossover studies have claimed clinical benefit. ${ }^{20-22}$ We therefore designed a large prospective 12 month placebo controlled trial to evaluate the clinical effects of fish oil supplementation in ulcerative colitis.

\section{Methods}

\section{TRIAL DESIGN}

The trial was designed as a randomised explanatory ${ }^{23}$ placebo controlled study of the effects of fish oil compared with olive oil. Trial medication was added to conventional treatment with sulphasalazine or mesalazine, and corticosteroids. Trial entry was stratified according to disease status at entry. The main endpoint was the relapse rate for all patients achieving stable remission (as defined below) during the trial. Other endpoints included (a) overall time spent in remission during the trial, (b) treatment of relapse: rate of achieving remission off corticosteroids, and corticosteroid dosage at one and two months.

\section{PATIENTS}

The study was performed in two centres, University Hospital, Nottingham, and Derbyshire Royal Infirmary, Derby, UK. Ethical approval was granted by the hospitals' ethical committees and patients gave informed written consent. Patients with ulcerative colitis diagnosed on the basis of rectal biopsy and barium enema or colonoscopy were enrolled. Entry was restricted to patients who had had two or more relapses in the previous three years.

\section{DEFINITIONS OF CLINICAL STATUS}

Patients were defined as being in remission if they had no symptoms of active disease for more than four weeks (rectal bleeding, loose stools, bowel frequency or other symptoms regarded by the patient as active disease), were not taking 
corticosteroids, and had uninflamed rectal mucosa (grade 0 or 1 ) at sigmoidoscopy. ${ }^{24}$ Patients in relapse were defined as those with active symptoms and/or inflamed rectal mucosa (sigmoidoscopic grade 2 or 3 ). Patients in relapse at trial entry were not enrolled until their clinical course had allowed the dose of prednisolone to be reduced to $20 \mathrm{mg}$ or below, to ensure that those whose colitis was deteriorating, or who were likely to require surgery, were excluded.

\section{TREATMENT}

\section{Trial medication}

Randomisaton was carried out by the hospital pharmacy in blocks of four to receive fish oil triglyceride concentrate HiEPA, $10 \mathrm{ml}$ twice daily or olive oil placebo $10 \mathrm{ml}$ twice daily for one year (Scotia Pharmaceuticals, Surrey, UK). The oils were stored in bottles under an atmosphere of nitrogen, at $4^{\circ} \mathrm{C}$. The oils were administered in unencapsulated form as initial evaluation showed that patients found it hard to swallow sufficient gelatin capsules to administer this volume, either because of their size $(1 \mathrm{ml})$ or the number required (20/day). The oils were referred to as food oils and patients were asked not to comment on the taste of the oils to the clinician. The composition of the oils is shown in Table I. Patients were asked to continue with their normal diet during the trial.

\section{Other medication}

Longterm medication with sulphasalazine or mesalazine was continued during the trial and patients kept a daily symptom diary including corticosteroid dose. Relapses were treated with prednisolone according to a defined protocol: $40 \mathrm{mg}$ daily for week one, $30 \mathrm{mg}$ daily for week two, then after assessment either $20 \mathrm{mg}$ daily in week three, and $10 \mathrm{mg}$ daily in week four, or $30 \mathrm{mg}$ and $20 \mathrm{mg}$ respectively if improvement was slow. Dosage was then reduced according to clinical need with every effort made to withdraw prednisolone as soon as practicable.

ASSESSMENT DURING THE TRIAL

Patients were assessed at one to three baseline pretreatment visits, and after one month, two months, and then two month intervals for one year ( $365 \pm 10$ days). Patients made unscheduled visits if symptoms suggesting relapse developed. Sigmoidoscopy and rectal biopsy were performed at baseline, two, six, and 12 months, or at unscheduled visits. St Marks forceps (KeyMed, Southend on Sea, UK) were used for rectal biopsy. After the procedure cotton wool swabs were applied to the biopsy site with gentle pressure for 10 second intervals and the time until no further obvious oozing of blood occurred was taken as a measure of haemostasis.

\section{Compliance}

Treatment compliance was assessed by a count of bottles of oil used per two month period, diary records of daily oil consumption, and measure- ment of red cell membrane eicosapentaenoic acid incorporation. Dietary intake of patients enrolled in Nottingham was assessed by two seven day semi weighed diet diaries (within the first two months and last two months of the study) and patients were given charts and instructions by a dietician. Calculations were made using the Microdiet version 7 computer program, with a database expanded ${ }^{25-27}$ to include current manufacturers' specifications of margarine, oil and salad dressing composition.

\section{BIOCHEMICAL STUDIES}

The following biochemical studies were performed; before, during, and two months after trial completion, in 66 patients enrolled in Nottingham:

\section{Membrane fatty acids}

Changes in red cell membrane fatty acids were monitored as the primary measure of compliance with oil supplementation. Red cell lipids were extracted into chloroform:methanol (1:2), methylated, and analysed by gas chromatography, as previously described. ${ }^{5}$ Rectal mucosal fatty acids were monitored to assess whether intended biochemical changes were achieved in the target tissue. Biopsy specimens were homogenised, and lipids extracted and analysed as for red cells.

\section{Synthesis of lipoxygenase products by ionophore stimulated peripheral blood neutrophils}

Neutrophils were isolated from peripheral blood by dextran sedimentation of red cells, and gradient centrifugation, and stimulated with calcium ionophore for five minutes, at $37^{\circ} \mathrm{C}$. Supernatants were analysed by reverse phase high pressure liquid chromatography as described previously.

\section{STATISTICS AND POWER}

Baseline characteristics were compared in the two treatment groups by $\chi^{2}$ test, unpaired $t$ test or Mann Whitney test as appropriate. Rate of relapse or of achieving remission were assessed by $\log$ rank analysis and the Kaplan Meier method. The number of trial days spent in remission was assessed by the Kolmogorov

TABLE I Composition of oil supplements

\begin{tabular}{llll}
\hline $\begin{array}{l}\text { Fatty acid } \\
\text { (chain length:no. double bonds) }\end{array}$ & Fish oil & Olive oil \\
\hline 14:0 $\quad$ Myristic acid & $8-11 \%$ & trace \\
16:0 $\quad$ Palmitic acid & $10-13 \%$ & $12 \%$ \\
18:0 $\quad$ Stearic acid & $2-4 \%$ & $2-3 \%$ \\
20:0 Arachidic acid & - & $0-1 \%$ \\
16:1 w7 Palmitoleic acid & $9-12 \%$ & $1 \%$ \\
18:1 w9 Oleic acid & $11-14 \%$ & $72 \%$ \\
18:2 w6 Linoleic acid & $4-6 \%$ & $11 \%$ \\
18:3 w6 Gamma-linolenic acid & - & $0-1 \%$ \\
$20: 4$ w6 Arachidonic acid & $3-5 \%$ & - \\
$20: 5$ w3 Eicosapentaenoic acid & $25 \%$ & - \\
$22: 6$ w3 Docosahexaenoic acid & $6 \%$ & - \\
alpha-tocopherol & - & $0 \cdot 06 \mathrm{ppm}$ \\
vitamin A & $7 \mathrm{mg} / \mathrm{kg}$ & - \\
\hline
\end{tabular}

*'Hiepa' oil had a peroxide value of $10 \mathrm{meq} \mathrm{O}_{2} / \mathrm{kg}$ oil, and acid value of $3 \mathrm{mg}$ potassium hydroxide/g oil. (ppm = parts per million) 
Smirnov test which compares cumulative frequency distribution. ${ }^{28}$ Corticosteroid dose in the relapse group at entry, and one, two, and four months was compared by Friedmans test.

Laboratory variables are expressed to two significant figures as mean or median with $95 \%$ confidence limits. For laboratory variables during the trial which were normally distributed the mean response at two, six, and 12 months was compared with the mean pretreatment value by paired $t$ test, having ascertained that there was no significant trends with time whilst on treatment, by repeated measures analysis of variance. Data which were non-normally distributed were likewise assessed by Friedman's two way analysis of variance and Wilcoxon's test. All tests were two tailed and $p<0.05$ was taken to be a significant response.

Patients with higher than average risk of relapse were recruited. To show a reduction in relapse rate over one year from $60 \%$ to $30 \%$, with a power (1- $\beta$ ) of 0.8 and $\alpha=0.05$ (two-tailed), 88 patients were required. ${ }^{29}$ Assuming a dropout rate of $10 \%, 97$ patients would need enrolling.

\section{Results}

ENROLMENT

Ninety six patients with ulcerative colitis were randomised in the trial, 76 in Nottingham and 20 in Derby. Fifty six patients entered in relapse; 26 randomised to fish oil and 30 to olive oil. Forty entered in remission; 20 randomised to each treatment. Nine patients (three relapse entry, six remission entry) withdrew from the trial in the first three months. These patients were similar to those who remained in the trial; one had total colitis, two had left sided colitis, six had sigmoid disease. The median duration of disease was 13 years. The main reasons for withdrawal were unpleasant taste of the oil (four olive oil, one fish oil) or domestic reasons (moving from the area, etc, three fish oil). One patient developed pruritus

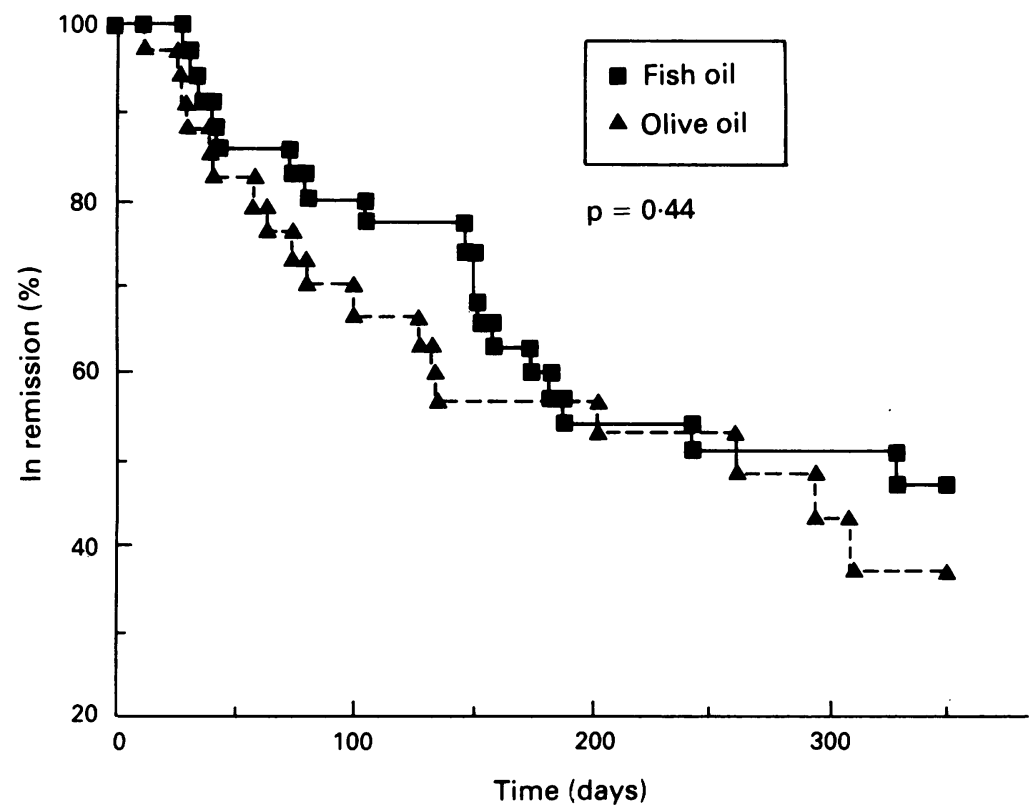

Figure 1: Kaplan-Meier plot of relapse rate for all patients entering the trial in remission or achieving remission for longer than four weeks during the trial, in fish oil $(n=35)$ or olive oil $(n=34)$.
TABLE II Baseline patient characteristics

\begin{tabular}{lll}
\hline & $\begin{array}{l}\text { Fish oil } \\
n=45\end{array}$ & $\begin{array}{l}\text { Olive oil } \\
n=42\end{array}$ \\
\hline Mean age (range) & $44(17-73)$ & $\begin{array}{l}49(20-77) \\
17: 25 \star\end{array}$ \\
Sex, male:female & $31: 14$ & \\
Disease distribution (\%): & $15(33 \%)$ & $18(43 \%)$ \\
$\quad$ total & $12(27 \%)$ & $10(24 \%)$ \\
left sided & $17(38 \%)$ & $14(33 \%)$ \\
sigmoid & $1(2 \%)$ & $0(0 \%)$ \\
proctitis & 7 & 9 \\
Mean duration of colitis (yr) & 2 & 3 \\
Median no of relapses in past 3 years & 1 & 1 \\
Smokers (n) & $38(84 \%)$ & $30(71 \%)$ \\
(\%) taking sulphasalazine or & $3(7 \%)$ & $2(5 \%)$ \\
mesalazine (n) & & \\
\hline (\%) taking NSAID's (n) & &
\end{tabular}

${ }^{\star} \mathrm{p}<0.05$. No other significant differences between groups.

after three months (olive oil) and was withdrawn because of the possibility that this was treatment related.

Characteristics of the 87 patients who remained in the study and whose results were analysed are shown in Table II. The groups were well matched apart from sex distribution. Because the trial was explanatory, data from the nine excluded patients were not included in primary analyses. A secondary analysis which regarded them as treatment failures was also performed.

COMPLIANCE

Patients in both groups recorded a median consumption of $20 \mathrm{ml}$ oil daily (interquartile range $20-20 \mathrm{ml}$ for fish oil, $15-20 \mathrm{ml}$ for olive oil), and bottle counts showed a median of 650 (360-720) ml per month in patients taking fish oil and $635(270-720) \mathrm{ml}$ per month in patients taking olive oil, with no fall during the year. Good compliance was confirmed by red cell membrane incorporation of eicosapentaenoic acid which rose from a baseline of $0.86 \%(0.58$

TABLE III Dietary fat intake during supplementation with fish oil or olive oil; data obtained from two seven day semi weighed diet diaries during the first two months and last two months of the trial as described in text, including contribution from the supplements themselves. Data as daily intake: mean (95\% confidence intervals)

\begin{tabular}{|c|c|c|c|}
\hline & $\begin{array}{l}\text { Fish oil } \\
n=28\end{array}$ & $\begin{array}{l}\text { Olive oil } \\
n=26\end{array}$ & \\
\hline Energy from fat (\%) & $\begin{array}{l}43 \\
(41-45)\end{array}$ & $\begin{array}{l}43 \\
(41-45)\end{array}$ & ns \\
\hline Total saturated fat (g) & $\begin{array}{l}53 \\
(41-66)\end{array}$ & $\begin{array}{l}50 \\
(43-58)\end{array}$ & ns \\
\hline $\begin{array}{l}\text { Total mono-unsaturated } \\
\text { fat }(\mathrm{g})\end{array}$ & $(34-51)$ & $\begin{array}{l}48 \\
(44-52)\end{array}$ & ns \\
\hline $\begin{array}{l}\text { Total polyunsaturated } \\
\text { fat (g) }\end{array}$ & $\begin{array}{l}24 \\
(20-28)\end{array}$ & $\begin{array}{l}20 \\
(16-23)\end{array}$ & ns \\
\hline $\begin{array}{l}\text { Polyunsaturated: } \\
\text { saturated fat ratio }\end{array}$ & $\begin{array}{l}0.51 \\
(0.42-0.59)\end{array}$ & $\begin{array}{l}0.46 \\
(0.34-0.59)\end{array}$ & ns \\
\hline $16: 0(\mathrm{~g})$ & $\begin{array}{l}28 \\
(23-34)\end{array}$ & $(24-33)$ & ns \\
\hline $18: 0(\mathrm{~g})$ & $\begin{array}{l}12 \\
(9-14)\end{array}$ & $\begin{array}{l}11 \\
(9-13)\end{array}$ & ns \\
\hline $16: 1(\mathrm{~g})$ & $\begin{array}{l}5 \cdot 0 \\
(3 \cdot 7-6 \cdot 2)\end{array}$ & $\begin{array}{l}2 \cdot 3 \\
(2 \cdot 0-2 \cdot 6)\end{array}$ & $\mathrm{p}<0.0001$ \\
\hline $18: 1(\mathrm{~g})$ & $\begin{array}{l}35 \\
(27-43)\end{array}$ & $\begin{array}{l}44 \\
(40-47)\end{array}$ & $p=0.051$ \\
\hline $20: 1(\mathrm{~g})$ & $\begin{array}{l}1 \cdot 0 \\
(0 \cdot 5-1 \cdot 5)\end{array}$ & $\begin{array}{l}0 \cdot 8 \\
(0 \cdot 6-1 \cdot 0)\end{array}$ & ns \\
\hline $18: 2(\mathrm{~g})$ & $(15-19)$ & $(14-21)$ & ns \\
\hline $18: 3(\mathrm{~g})$ & $\begin{array}{l}1 \cdot 7 \\
(0 \cdot 8-2 \cdot 6)\end{array}$ & $\begin{array}{l}1 \cdot 5 \\
(1 \cdot 2-1 \cdot 9)\end{array}$ & ns \\
\hline $20: 4(\mathrm{~g})$ & $\begin{array}{l}0.9 \\
(0.8-0.9)\end{array}$ & $\begin{array}{l}0 \cdot 2 \\
(0 \cdot 1-0 \cdot 2)\end{array}$ & $p<0.0001$ \\
\hline $20: 5(\mathrm{~g})$ & $\begin{array}{l}4 \cdot 8 \\
(4 \cdot 7-4 \cdot 8)\end{array}$ & $\begin{array}{l}0 \cdot 3 \\
(0 \cdot 2-0 \cdot 4)\end{array}$ & $\mathrm{p}<0.0001$ \\
\hline $22: 6(\mathrm{~g})$ & $\begin{array}{l}1 \cdot 2 \\
(1 \cdot 2-1 \cdot 3)\end{array}$ & $\begin{array}{l}0 \cdot 2 \\
(0 \cdot 1-0 \cdot 3)\end{array}$ & $\mathrm{p}<0.0001$ \\
\hline
\end{tabular}


TABLE IV Patients entering trial in relapse: dose of prednisolone in mg at trial entry and during follow up, median and interquartile range

\begin{tabular}{lll}
\hline & $\begin{array}{l}\text { Fish oil } \\
n=26\end{array}$ & $\begin{array}{l}\text { Olive oil } \\
n=27\end{array}$ \\
\hline Trial entry & $10^{\text {ns }}$ & 10 \\
& $(0-10)$ & $(4-15)$ \\
1 month & $5^{\star} \ddagger$ & 8 \\
& $(0-5)$ & $(3-10)$ \\
2 months & $0^{\star} \dagger$ & 5 \\
& $(0-5)$ & $(1 \cdot 5-12 \cdot 5)$ \\
\hline
\end{tabular}

${ }^{\star} p=0.01$, compared with olive oil group; $\uparrow p<0.05 ; \ddagger p<0.01$, compared with baseline; ns=not significant, compared with olive oil group.

$1 \cdot 15)$ total lipids [median ( $95 \%$ confidence intervals)], to $4 \cdot 7 \%(4 \cdot 0-5 \cdot 2)$ at two months, $4 \cdot 9 \%$ $(3 \cdot 8-6 \cdot 3)$ at six months, and 5.5\% (3.6-6.2) at 12 months, in the fish oil group, $(\mathrm{p}<0.0001)$ compared with baseline. Two months after stopping fish oil, eicosapentaenoic acid levels were still raised significantly at $2 \cdot 1 \%(1 \cdot 6-2 \cdot 8), \mathrm{p}=0 \cdot 0015$. There was no significant increase in eicosapentaenoic acid in the olive oil group.

\section{DIET}

The fat composition of the supplemented diets are shown in Table III, with significantly greater levels of eicosapentaenoic acid, docosahexaenoic acid and arachidonic acid in the fish oil group, and a trend towards greater oleic acid levels in the olive oil group. Intake of fish was very low in both treatment groups, with a mean daily consumption of $0.25 \mathrm{~g}$ eicosapentaenoic acid in the fish oil group, and $0.3 \mathrm{~g}$ eicosapentaenoic acid in the olive oil group, equivalent to approximately $175-210 \mathrm{~g}$ fish per week. There was no significant change in weight during the trial in either group.

\section{CLINICAL RESPONSE}

\section{Maintenance of remission}

Nineteen patients on fish oil and 15 on olive oil

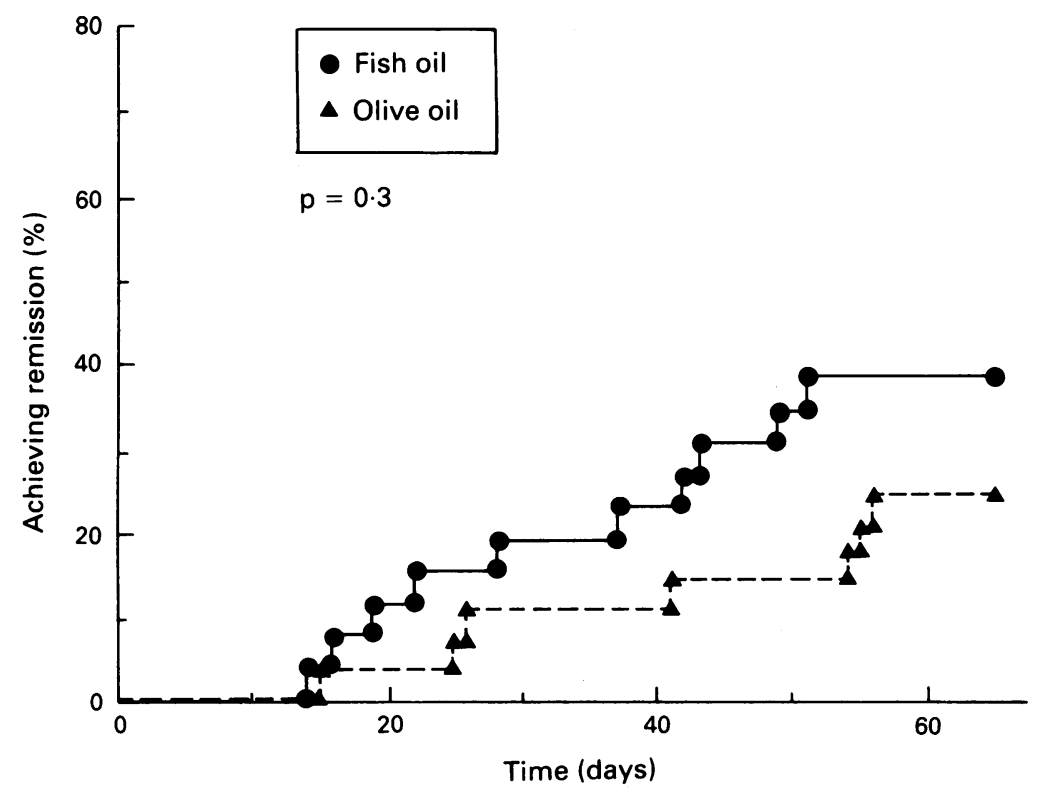

Figure 2: Kaplan Meier plot of rate of achieving remission off corticosteroids over two months for patients entering the trial in relapse. Fish oil $(n=26)$ or olive oil $(n=27)$. entered the trial in remission, and a further 16 and 19 patients respectively achieved remission of greater than four weeks during the trial, giving a total of 69 patients, 35 fish oil and 34 olive oil. Forty two per cent of the patients taking fish oil relapsed within six months (versus $43 \%$ of patients taking olive oil). At one year the proportions were $54 \%$ for fish oil and $63 \%$ for olive oil (not significant, $p=0.44$, Fig 1 ).

Because those patients entering the trial in relapse generally had more active disease, compared with those patients entering in remission (as shown below), relapse rate of the subgroup of patients entering the trial in remission (19 on fish oil, 15 on olive oil), was also analysed separately. There was a trend for patients on fish oil to relapse later: $25 \%$ of patients taking fish oil relapsed by six months, compared with $40 \%$ for olive oil, but at one year the proportions were $42 \%$ for fish oil and $48 \%$ for olive oil (no significant difference, $\mathrm{p}=0.54)$.

Patients on fish oil tended to spend more time in remission than those on olive oil but the differences did not achieve statistical significance. For the total trial group, patients taking fish oil spent a median 230 days in remission compared with 208 days for patients taking olive oil (not significant when analysed by the Kolmogorov Smirnov test). Patients who entered the study in remission and received fish oil spent 365 (265-365) days [median (interquartile range)] in remission compared with $349(240-365)$ days for comparable patients taking olive oil. For those entering in relapse the comparable figures are 98 (0-224) days for fish oil, and $101(0-248)$ for olive oil.

On an intention to treat analysis of all 96 patients, regarding all dropouts as treatment failures, the differences were again not significant.

\section{Treatment of relapse}

The median corticosteroid dosage at entry for patients in relapse was $10 \mathrm{mg}$ for both fish oil and olive oil groups (Table IV). Patients on fish oil had reduced corticosteroid requirements at one (5 mg) and two months (nil), compared with the olive oil group $(8 \mathrm{mg}$ at one month and $5 \mathrm{mg}$ at two months, $p=0.01$, at both one and two months). The difference in corticosteroid consumption at one and two months remains equally significant when analysed on an intention to treat basis.

Analysing the time to achieve remission off corticosteroids by the log rank method (Fig 2), $20 \%$ of patients taking fish oil versus $11 \%$ on olive oil achieved remission off corticosteroids by one month, and $39 \%$ on fish oil, versus $29 \%$ on olive oil at two months. This trend towards earlier remission on fish oil (corresponding to the corticosteroid sparing effect), however, did not achieve statistical significance $(p=0 \cdot 3)$.

\section{Effects of other drugs}

Patients on sulphasalizine or mesalazine during the trial $(n=68)$ spent more days in remission, 215 days (183-248), [median (interquartile range)], than those not taking salicylates, 146 
TABLE V Fatty acid content of rectal biopsies, expressed as per cent total lipids, during trial. Median ( $95 \%$ confidence interval)

\begin{tabular}{lllll}
\hline & Basal & 2 months & 6 months & 12 months \\
\hline Fish oil patients & & & & \\
AA $^{\text {as }}$ & $7 \cdot 3$ & $6 \cdot 7$ & $8 \cdot 0$ & $6 \cdot 8$ \\
& $(6 \cdot 0-8 \cdot 7)$ & $(5 \cdot 6-7 \cdot 8)$ & $(5 \cdot 6-10)$ & $(5 \cdot 2-8 \cdot 3)$ \\
EPA $^{\star}$ & $0 \cdot 4$ & $2 \cdot 8$ & $3 \cdot 2$ & $2 \cdot 1$ \\
& $(0-0 \cdot 58)$ & $(1 \cdot 6-4 \cdot 0)$ & $(1 \cdot 6-3 \cdot 9)$ & $(1 \cdot 8-4 \cdot 2)$ \\
DHA $^{\text {ns }}$ & $1 \cdot 4$ & $1 \cdot 8$ & $1 \cdot 6$ & $1 \cdot 6$ \\
& $(1 \cdot 1-1 \cdot 7)$ & $(1 \cdot 2-2 \cdot 4)$ & $(1 \cdot 2-1 \cdot 9)$ & $(0 \cdot 98-2 \cdot 2)$ \\
Olive oil patients & & & & \\
AA $^{\text {ns }}$ & $7 \cdot 7$ & $8 \cdot 2$ & 11 & $10+$ \\
EPA $^{\text {ns }}$ & $(6 \cdot 5-8 \cdot 9)$ & $(6 \cdot 9-9 \cdot 5)$ & $(5 \cdot 4-18)$ & $(8 \cdot 9-12)$ \\
& $0 \cdot 42$ & $0 \cdot 41$ & $0 \cdot 63$ & 0 \\
DHA $^{\text {ns }}$ & $(0-0 \cdot 9)$ & $(0-1 \cdot 5)$ & $(0-1 \cdot 2)$ & $(0-0 \cdot 82)$ \\
& $1 \cdot 5$ & $1 \cdot 7$ & $1 \cdot 5$ & $1 \cdot 3$ \\
& $(1 \cdot 2-1 \cdot 9)$ & $(1 \cdot 4-2 \cdot 0)$ & $(1 \cdot 1-1 \cdot 8)$ & $(0 \cdot 92-1 \cdot 7)$ \\
\hline
\end{tabular}

${ }^{\star} p=0.0001$, mean response compared to basal value; $\nmid p<0.01$, compared with patients on fish oil.

days $(80-212), n=19, p=0.056$. For the 69 patients in remission during the trial, of 35 taking fish oil, $32(91 \%)$ were taking sulphasalazine or mesalazine (5-aminosalicylic acid preparations). Of the 34 on olive oil, $23(68 \%)$ were taking 5-aminosalicylic acid preparations, a significant difference, $\left(\chi^{2}=4.65, p<0.05\right)$. When only the patients taking sulphasalazine or mesalazine were analysed, 17 of $32(53 \%)$ patients relapsed on fish oil and a 5-aminosalicylic acid preparation, and 11 of the $23(48 \%)$ patients on olive oil and 5-aminosalicylic acid preparations relapsed (not significant).

Of patients entering the study in relapse, 21 of $26(81 \%)$ allocated fish oil were taking 5 -aminosalicylic acid derivatives, and 19 of $27(70 \%)$ allocated olive oil $\left(\chi^{2}=0 \cdot 3, p=n s\right)$. Again, when analysis was restricted to the 5 aminosalicylic acid preparation users, there was still a significant reduction in prednisolone dose for fish oil patients (1 mg (0-5) (median (interquartile range)) at one month, $0 \mathrm{mg}(0-5)$ at two, compared with olive oil, $6 \mathrm{mg}(3-11)$ at one month, and $5 \mathrm{mg}(1-10)$ at two months.

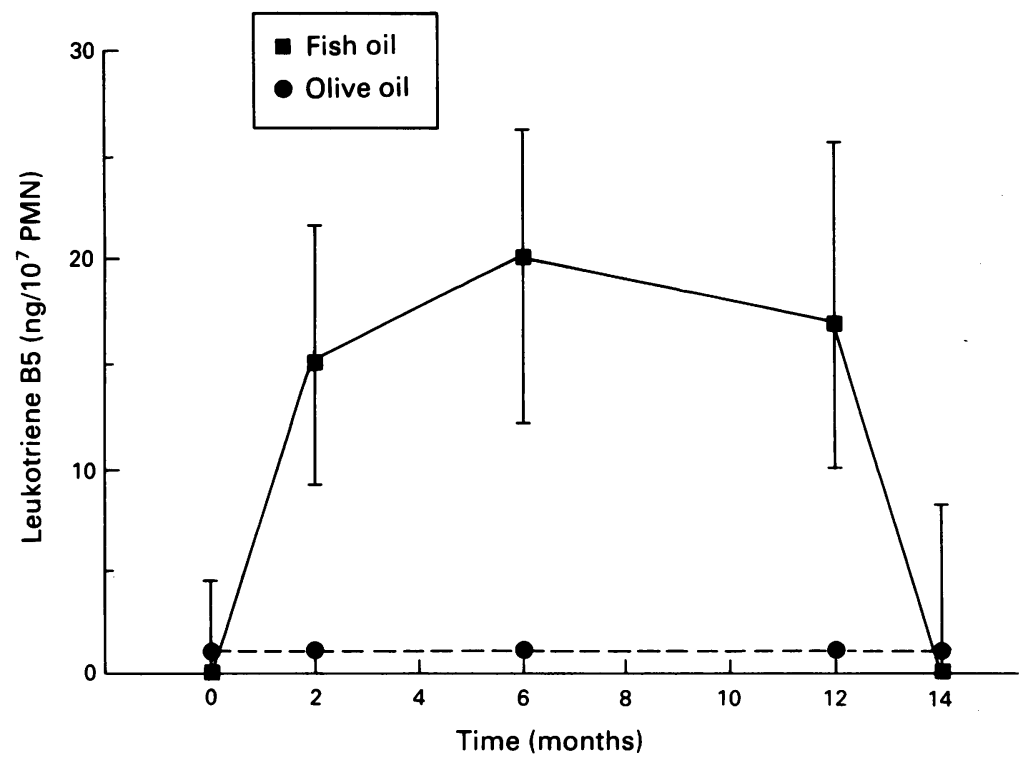

Figure 3: Leukotriene B5 synthesis by peripheral blood neutrophils stimulated ex vivo by ionophore $5 \mu M$ for 5 minutes. Measured by high pressure liquid chromatography before, ionophore $5 \mu M$ for 5 minutes. Measured by high pressure liquid chromatography before,
during, and two months after oil supplementation; and expressed as median and $95 \%$ confidence intervals. Fish oil $n=24$, olive oil $n=22$. Fish oil response during trial $p<0.0001$ (mean treatment response compared with baseline).

\section{ADVERSE EFFECTS}

Oils were stopped in three subjects because of clinical events deemed possibly treatment related. One patient experienced pruritus after three months and treatment was withdrawn, and one patient with atopic eczema stopped treatment at six months because of worsening eczema (both on olive oil). One patient with chronic asthma normally controlled on salbutamol and beclomethasone inhalers, experienced worsening asthma at seven months, and oil was stopped (fish oil).

\section{HAEMOSTASIS}

At the end of the trial the time for bleeding to cease after mucosal biopsy was 25 (median, interquartile range 20-35) seconds for patient taking fish oil compared with $25(20-40)$ seconds, for patients taking olive oil (not significant).

\section{FATTY ACID LEVELS IN RECTAL MUCOSA}

In patients taking fish oil, eicosapentaenoic acid levels rose significantly at all follow up visits $(\mathrm{p}<0.0001)$, Table V. Arachidonic acid levels were similar in the two groups at baseline, but at the end of the trial were significantly lower $(6 \cdot 8 \%$ versus $10.5 \%$ ) in patients taking fish oil, compared with olive oil, $\mathrm{p}<0 \cdot 01$.

\section{SYNTHESIS OF LIPOXYGENASE PRODUCTS BY} IONOPHORE STIMULATED PERIPHERAL BLOOD NEUTROPHILS

\section{Leukotriene B5}

Before entry into the trial there was no detectable synthesis of leukotriene B5 in any patient. All patients treated with fish oil synthesised detectable amounts of leukotriene B5 within two months, peaking at a median synthesis of $20 \mathrm{ng} /$ $10^{7}$ neutrophils in response to $5 \mu \mathrm{M} \mathrm{A23187}$ by six months (Fig 3), $p=0.001$ compared with baseline. These levels persisted throughout the trial but were undetectable two months after stopping fish oil. Patients treated with olive oil did not synthesise detectable amounts of leukotriene B5.

\section{Leukotriene B4}

Synthesis of leukotriene B4 at all concentrations of ionophore was significantly suppressed after two months treatment with fish oil and did not vary significantly thereafter. Thus, leukotriene B4 synthesis in response to ionophore $1.25 \mu \mathrm{M}$ was suppressed by $49 \%, 53 \%$ and $59 \%$ compared with baseline after two, six, and 12 months treatment with fish oil $(\mathrm{p}<0.001)$, Fig 4 . Two months after stopping fish oil, leukotriene B4 synthesis stimulated by ionophore $1.25 \mu \mathrm{M}$ remained significantly suppressed compared with baseline $(p<0.05)$

There were no significant changes in leukotriene B4 synthesis during the trial in patients taking olive oil. Two months after stopping olive oil, however, there was a significant and unexplained fall in the synthesis of leukotriene B4 stimulated by ionophore $1.25 \mu \mathrm{M}(\mathrm{p}=0.001)$. 


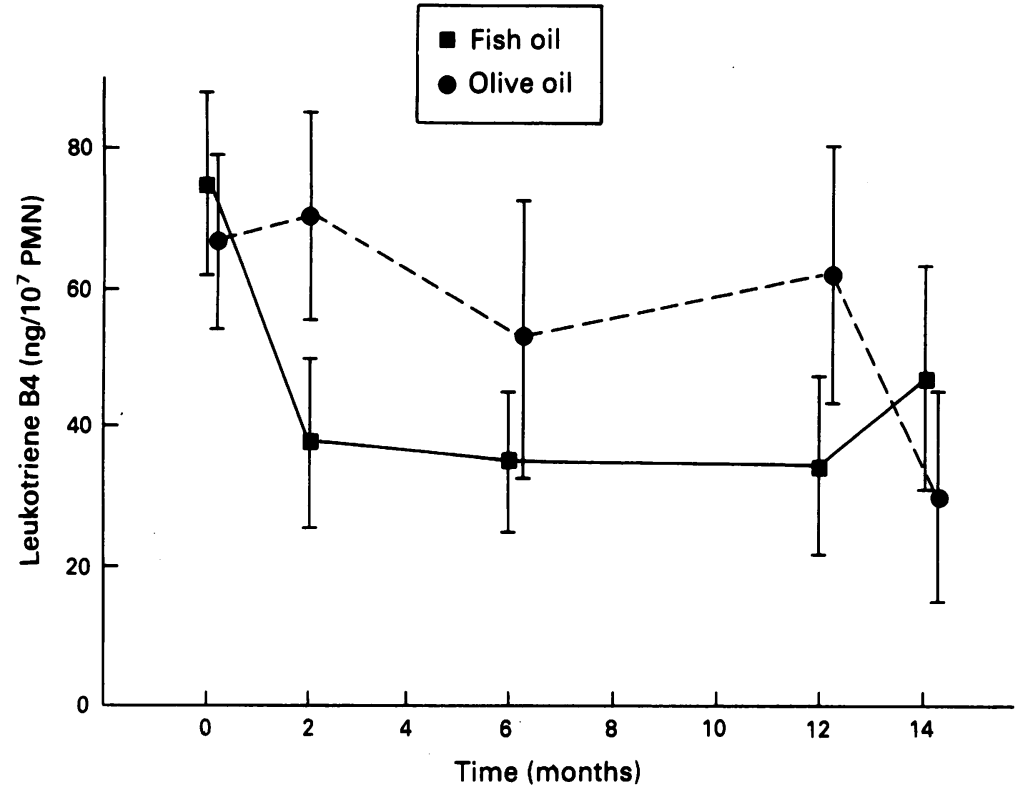

Figure 4: Leukotriene B4 synthesis by peripheral blood neutrophils stimulated ex vivo by ionophore 1.25 $\mu \mathrm{M}$ for five minutes, measured by high pressure liquid chromatography before, during and two months after oil supplementation, expressed as mean and $95 \%$ confidence intervals. Fish oil $n=24$, olive oil $n=22$. Fish oil patients' response $p<0.001$ (mean treatment response compared with baseline). At 14 months response still reduced compared to baseline $(p<0.05)$. No significant changes in olive oil group.

Using data from all patient visits, prednisolone dosage correlated negatively with leukotriene B4 synthesis $\left(\mathrm{R}_{\mathrm{s}}=-0 \cdot 2, \mathrm{n}=228, \mathrm{p}=0.002\right)$, but there were no significant differences with use of sulphasalazine or mesalazine.

\section{Discussion}

This study shows that prolonged compliance with fish oil treatment can be achieved despite its somewhat unpleasant taste. Longterm use appears to be safe and achieves a significant enhancement of overall n-3 fatty acid intake resulting in sustained increases in membrane levels of eicosapentaenoic acid with enhanced synthesis of leukotriene B5 and a halving of leukotriene B4. In contrast with other studies where fish oil has been given for shorter periods, these effects persisted at the two month post treatment assessment. It is possible that prolonged treatment results in a build up of stores of eicosapentaenoic acid in low turnover sites in membrane phospholipids, or in low turnover tissue such as fat. We anticipated that these longterm changes would be most likely to result in a change in the natural history of ulcerative colitis over one year, and designed the study accordingly. As a secondary objective the study was also structured to detect an effect on the treatment of relapse.

In the treatment of active colitis, there is a significant corticosteroid sparing effect at one and two months. The dose reduction was modest, because patients with acute relapse, requiring high dose prednisolone, were not enrolled until their disease was coming under control and they were on less than $20 \mathrm{mg}$ of prednisolone, to avoid enrolling patients likely to require surgery. It seems probable that a trial directed specifically at relapse with fish oil started at the same time as corticosteroid therapy would show a numerically larger effect. For patients who are corticosteroid dependent, even this modest reduction in prednisolone requirements may be useful in limiting cortico-steroid related side effects. Patients entering in relapse were well matched for use of 5-aminosalicylic acid preparations, and even when analysis was restricted to patients taking sulphasalazine or mezalazine, there was still a statistically significant reduction in prednisolone requirement. In a trial of the orally active 5-lipoxygenase inhibitor zileuton (A64077), ${ }^{30}$ benefit in treatment of relapse was restricted to those patients not taking 5-aminosalicylic acid preparations, although the study design was different in that patients were not taking concomitant prednisolone in that study.

Clinical benefit must not necessarily be attributed to inhibition of leukotriene synthesis, as there is evidence of a number of other anti inflammatory actions of fish oil, including suppression of interleukin-1 synthesis, ${ }^{31}$ platelet activating factor ${ }^{32}$ and free radical scavenging, ${ }^{33}$ and alteration of membrane fluidity and inhibition of platelet aggregation..$^{34}$

There are several possible reasons for the failure to show a significant effect on maintenance of remission. First, greater than $50 \%$ suppression of leukotriene B4 synthesis may be required for clinical benefit. Trials of potent, selective 5-lipoxygenase inhibitors giving $80-90 \%$ inhibition should clarify this. Second, an effect of fish oil might have been obscured if the olive oil placebo was therapeutically active. There is no clear evidence of this, although it has been suggested that the squalene present in olive oil (hexamethyltetracosahexane $\mathrm{C}_{30} \mathrm{H}_{50}$ ) acts as a free radical scavenger, and gives benefit in occlusive vascular disease. ${ }^{35}$ This is unlikely, however, as the fatty acids in olive oil are already present in significant amounts in the normal diet, and olive oil treatment did not affect membrane fatty acid composition, or neutrophil function.

Third, it is possible that concomitant treatment with prednisolone and 5-aminosalicylic acid containing drugs may have obscured a true benefit. In support of this we have shown a significant negative correlation between prednisolone dose and neutrophil leukotriene B4 synthesis. It would have been unethical, however, to withold corticosteroid therapy in patients with active disease and we selected corticosteroid sparing as an end point in the study, administering them to a strict protocol, so that corticosteroid consumption reflected disease activity. Similarly, benefit from fish oil may have been more apparent if our patients were not taking 5-aminosalicylic acid preparations. The number of patients not taking these drugs were too small to analyse, however, and we were reluctant to stop these drugs in those established on them.

Other studies have provided evidence of benefit from fish oil in inflammatory bowel disease. In the rat TNB colitis model of granulomatous colitis, pretreatment with cod liver oil resulted in reduced colonic damage scores, less chronic fibrosis, and reduced thromboxane and leukotriene B4 synthesis. ${ }^{1213}$ In human studies, MaxEPA (18 g/day) has been shown to increase eicosapentaenoic acid content of colonic mucosa, and in a 12 week open study disease activity was reported to decline..$^{20}$ In another open study over 
eight weeks improvement in seven of 10 patients was also reported with dose reductions in four of five on prednisolone. ${ }^{22}$ These open studies must be interpreted cautiously in view of the relapsing and remitting course of ulcerative colitis and the lack of blinding and controls. The only other controlled study to date was a double blind crossover trial comparing four months MaxEPA with vegetable oil, with a one month washout. ${ }^{21}$ This showed improvement in sigmoidoscopy score and global clinical assessment on MaxEPA. The likelihood of a carry over effect is high, in view of our data showing persisting biochemical effects at two months.

In conclusion, although the study did not show that fish oil supplements increased the time spent in remission over one year, there was a significant corticosteroid sparing effect in active disease. This warrants further investigation including a comparison with zileuton, as benefit was apparent in patients receiving corticosteroids or 5-aminosalicylic acid preparations. Supported by a research grant from Scotia Pharmaceuticals
$(\mathrm{ABH})$, and the British Digestive Foundation $(\mathrm{CJH})$. We are $(\mathrm{ABH})$, and the British Digestive Foundation (CJH). We are
grateful to the following for their help in this study: Dr S D grateful to the following for their help in this study: Dr S D
Horrobin and C Stewart of Scotia Pharmaceuticals for their advice Horrobin and C Stewart of Scotia Pharmaceuticals for their advice
and support; D. Spiegelheter of the MRC statistics unit, Cam-
bridge, and J Pearson and P Riley of Nottingham University for bridge, and J Pearson and P Riley of Nottingham University for
statistical advice; and Sister M Parker for the use of facilities in the statistical advice;

Previously submitted in abstract form to the American Gastroenterology Association Meeting, San Antonio, Texas, May 1990.

1 Ford-Hutchinson AW. Leukotriene B, a potent chemokinetic and aggregating substance release from polymorphonuclear leucocytes. Nature 1980; 286: 264-5.

2 Sharon P, Stenson WF. Enhanced synthesis of leukotriene B4 by colonic mucosa in inflammatory bowel disease. Gastroenterology 1984; 86: 453-60.

3 Lobos EA, Sharon P, Stenson WF. Chemotactic activity in inflammatory bowel disease. Role of leukotriene B4. Dig Dis Sci 1987; 32: 1380-8.

4 Lee TH, Hoover RL, Williams D, Sperling RI, Ravalese J, Spur BW, et al. Effect of dietary enrichment with eicosapentaenoic acid and docosahexaenoic acids on in vitro polymorphonuclear and monocyte leukotriene generation and polymorphonuclear leucocyte function. $N \mathrm{Engl} \mathcal{F} \mathrm{Med}$ 1985; 312: 1217-24.

5 Hawthorne AB, Filipowicz BL, Edwards TJ, Hawkey CJ. High dose eicosapentaenoic acid ethyl ester: effects on lipids and neutrophil leukotriene production in normal volunteers. Br f Clin Pharmacol 1990; 30: 187-94.

6 Prescott L, Zimmerman GA, Morrison AR. The effects of a diet rich in fish oil on human polymorphonuclear leucocytes; identification of LTB5 as a metabolite. Prostaglandins 1985 ; 30: 209-27.

7 Goldman DW, Pickett WC, Goetzl EJ. Human neutrophil chemotactic and degranulating activities of leukotriene BS (LTB5) derived from eicosapentaenoic acid. Biochem Biophys Res Commun 1983; 117: 282-8.

8 Lee TH, Mencia-Huerta J-M, Shih C, Corey EJ, Lewis RA Austen KF, et al. Characterization and biological propertie of 5,12 , dihydroxy derivatives of eicosapentaenoic acid, including LTB5 and the double lipoxygenase product. f Biol Chem 1984; 259: 2383-9.

9 Terano T, Hirai A, Tamura Y, Yoshida S, Salmon JA Moncada S. Effect of eicosapentaenoic acid on eicosanoids formation by stimulated human polymorphonuclear leukoformation by stimulated human polym
cytes. Prog Lipid Res $1986 ; 25: 129-37$.

10 Terano T, Salmon JA, Higgs GA, Moncada S. Eicosapentaenoic acid as a modulator of inflammation. Biochem Pharmacol 1986; 35: 779-85.
11 Robinson DR, Prickett JD, Makoul GT, Steinberg AD, Colvin RB. Dietary fish oil reduces progression of established renal disease in $(\mathrm{NZBxNZW}) \mathrm{Fl}$ mice and delays renal disease in BXSB and MRL/1 strains. Arthritis Rheum 1986; 29: $539-46$

12 Vilaseca J, Salas A, Guarner F, Rodriguez R, Martinez M, Malagelada $J-R$. Dietary fish oil reduces progression of chronic inflammatory lesions in a rat model of granulomatous chronic inflammatory lesions

13 Wallace JL, Keenan CM, Finn NJ. Anti-inflammatory effects of a fish oil diet in a rat model of chronic colitis. Gastroenterology 1989; 96: A535.

14 Bittiner SB, Tucker WFG, Cartwright SS, Bleehan SS. A double-blind randomized placebo-controlled trial of fish oil in psoriasis. Lancet 1988; i: 378-80.

15 Bjorneboe A, Soyland E, Bjorneboe G-EA, Rajka G, Drevon $\mathrm{CA}$. Effect of dietary supplementation with eicosapentaenoic acid in the treatment of atopic dermatitis. Brf Dermato 1987; 117: 463-9.

16 Kremer JM, Jubiz W, Michalek A, Rynes RI, Bartholomew LE, Bigaouette J, et al. Fish oil fatty acid supplementation in active rheumatoid arthritis. A double-blinded controlled crossover study. Ann Intern Med 1987; 106: 497-503.

17 Nishida T, Miwa H, Shigematsu A, Yamamoto M. Increased arachidonic acid composition of phospholipids in colonic mucosa from patients with active ulcerative colitis. $G u t$ mucosa from pa

18 Pacheco S, Hillier K, Smith C. Increased arachidonic acid levels in phospholipids of human colonic mucosa in inflammatory bowel disease. Clin Sci 1987; 73: 361-4

19 Hillier K, Dorrell L, Jewell R, Smith CL. Effect of dietary marine oil on human colon mucosa lipid fatty acids and prostaglandin synthesis in patients with inflammatory bowel disease. In: Lands WEM, ed. Polyunsaturated fatty acids and eicosanoids. Champaign, Illinois: American Oil Chemists Society, 1987: 481-6.

20 McCall TB, O'Leary D, Bloomfield J. Therapeutic potential of fish oil in the treatment of ulcerative colitis. Aliment Pharmacol Therap 1989; 3: 415-24.

21 Stenson WF, Cort D, Beeken W, Rodgers J, Burakoff R. A trial of fish oil supplemented diet in ulcerative colitis. Gastroenterology 1990; 98: A475.

22 Salomon P, Asher A, Kornbluth AA, Janowitz HD. Treatmen of ulcerative colitis with fish oil n-3-w-fatty acid: an open trial. F Clin Gastroenterol 1990; 12: 157-61.

23 Schwartz D, Lellouch J. Explanatory and pragmatic attitudes in therapeutical trials. $\mathcal{F}$ Chron Dis 1967; 20: 637-48.

24 Baron JH, Connell AM, Lennard-Jones JE. Variation between observers in describing mucosal appearances in proctocolitis. BMF 1964; 1: 89-92.

25 Wiles SJ, Nettleton PA, Black AE, Paul AA. The nutrient composition of some cooked dishes eaten in Britain: a supplementary food composition table. $\mathcal{F}$ Hum Nutr 1980; 34: 189-223.

26 Broadhurst AI, Wharf SG, Stockley L. Fatty acid composition of selected foods consumed in a mixed diet study. Hum Nutr of selected foods consumed in

27 Fehily AM, Phillips KM, Sweetnam PM. A weighed dietary survey of men in Caerphilly South Wales. Hum Nutr Appl Nutr 1984; 38: A270-6.

28 Siegel S. Non-parametric statistics for the behavioural sciences. Tokyo. McGraw-Hill Kogakusha, 1956: 127-31.

29 Machin D, Campbell MJ. Statistical tables for the design of clinical trials. Oxford: Blackwell; 1987.

30 Lauritsen K, Laursen LS, RAsk-Madsen J, Jacobsen O, Naesdal J, Stenson W, et al. Abbott-64077, a potent lipoxygenase inhibitor in the treatment of ulcerative colitis. Gastroenterology 1990; 98: A185.

31 Endres S, Ghorbani R, Kelley VE, Georgilis K, Lonneman G, Van Der Meer JWM, et al. The effect of dietary supplementation with n-3 polyunsaturated fatty acids on the mentation with $n-3$ polyunsaturated fatty acids on the synthesis of interleukin-1 and tumor necrosis fac
mononuclear cells. $N$ Engl F Med 1989; 320: 265-71.

32 Sperling RI, Weinblatt M, Robin JL, Ravalese J, Hoover RL House F, et al. Effects of dietary supplementation with marine fish oil on leukocyte lipid mediator generation and function in rheumatoid arthritis. Arthritis Rheum 1987; 30 988-97.

33 Magaro M, Altomonte L, Zoli A, Mirone L, De Sole P DiMario $\mathrm{L}$, et al. Influence of diet with different lipid composition on neutrophil chemiluminescence and disease activity in patients with rheumatoid arthritis. Ann Rheum Dis 1988; 47: 793-6.

34 Leaf A, Weber PC. Cardiovascular effects of n-3 fatty acids. N Engl F Med 1988; 318: 549-57.

35 Budiarso IT. Fish oil versus olive oil. (Letter). Lancet 1990 ; 336: $1313-4$. 